\title{
A Novel Amorphous Curcumin Preparation Improved Oral Absorption Efficiency in Healthy Volunteers: A Single-Dose, Double-Blind, Two-Way Crossover Study
}

\section{Yoichi Sunagawa \\ University of Shizuoka \\ Yusuke Miyazaki \\ University of Shizuoka \\ Masafumi Funamoto \\ University of Shizuoka \\ Kana Shimizu \\ University of Shizuoka}

Satoshi Shimizu

University of Shizuoka

Sari Nurmila

University of Shizuoka

Yasufumi Katanasaka

University of Shizuoka Library: Shizuoka Kenritsu Daigaku Toshokan

Masashi Ito

Therabiopharma Ltd

\section{Tatsuya Ogawa}

Therabiopharma Ltd

Hitomi Ozawa-Umeta

Therabiopharma Ltd

\section{Koji Hasegawa}

National Hospital Organisation Kyoto Medical Center: Kokuritsu Byoin Kiko Kyoto Iryo Center

Tatsuya Morimoto ( morimoto@u-shizuoka-ken.ac.jp)

University of Shizuooka

\section{Research}

Keywords: curcumin, oral absorption efficiency, amorphous, Theracurmin, CurcuRouge

Posted Date: November 13th, 2020 
DOl: https://doi.org/10.21203/rs.3.rs-104381/v1

License: (c) (1) This work is licensed under a Creative Commons Attribution 4.0 International License. Read Full License 


\section{Abstract}

Background: Curcumin has diverse biological activities such as anti-cancer, antioxidant, and antiinflammatory properties and is assumed to exhibit beneficial effects in the prevention and treatment of various diseases. Although curcumin is known to be safe in humans, its therapeutic efficacy is limited owing to its poor bioavailability. To overcome this problem, we prepared a novel curcumin preparation curcuRoug $\mathrm{e}^{\mathrm{TM}}$ using the amorphous solid dispersion method. In this study, we aimed to investigate the oral absorption efficiency of curcuRouge ${ }^{\mathrm{TM}}$ and compare its efficiency with that of Theracurmin ${ }^{\circledR}$, a highly absorptive curcumin preparation dispersed with colloidal submicron-particles exhibiting improved bioavailability, in rats and healthy volunteers.

Methods: In the animal experiment, male Sprague-Dawley rats were orally administered curcuRouge ${ }^{\mathrm{TM}}$ or Theracurmin ${ }^{\circledR}(10 \mathrm{mg} / \mathrm{kg}$ of curcumin). The plasma curcumin levels were measured at $0.25,0.5,1,2,4$, and $6 \mathrm{~h}$ after administration. In addition, we performed a single-dose, double-blind, two-way crossover study to compare plasma curcumin levels after the administration of curcuRouge ${ }^{\mathrm{TM}}$ or Theracurmin ${ }^{\circledR}$ in humans. Twelve healthy volunteers were administered curcuRouge ${ }^{\mathrm{TM}}$ or Theracurmin ${ }^{\circledR}$ containing $30 \mathrm{mg}$ curcumin. The plasma curcumin concentrations at $0.5,1,2,4$, and $8 \mathrm{~h}$ after ingestion were determined.

Results: The area under plasma concentration-time curve $\left(A U C_{0-6} \mathrm{~h}\right)$ and maximum plasma concentration $\left(C_{\max }\right)$ of curcuRouge ${ }^{\mathrm{TM}}$ in rats were 3.7- and 9.6-fold higher than those of Theracurmin ${ }^{\circledR}$, respectively. Twelve healthy volunteers were orally administered $90 \mathrm{mg}$ of curcuRouge ${ }^{\mathrm{TM}}$ or Theracurmin ${ }^{\circledR}$ in a randomized double-blind crossover study. In these volunteers, the $A U C_{0-8} \mathrm{~h}$ and $C_{\max }$ of curcuRouge ${ }^{\mathrm{TM}}$ were 3.4 -fold and 5.4-fold higher than those of Theracurmin ${ }^{\circledR}$, respectively.

Conclusion: These findings indicate that curcuRoug $\mathrm{e}^{\mathrm{TM}}$ shows better bioavailability than other highly absorptive curcumin preparations, such as Theracurmin ${ }^{\circledR}$. Hence, curcuRouge ${ }^{\mathrm{TM}}$ is assumed to exhibit clinical efficacy for managing various diseases at a low dose.

Trial registration: The trial was registered with the UMIN Clinical Trials Registry (January 8, 2020, UMIN000039083, https://upload.umin.ac.jp/cgi-open-bin/ctr_e/ctr_view.cgi?recptno=R000044573).

\section{Introduction}

The morbidity and mortality of lifestyle-related diseases, including type 2 diabetes, cardiovascular disease, and cancer, has increased in developed countries. As these diseases are caused by abnormalities in multiple signaling pathways because of environmental, genetic, and aging factors, it is difficult to prevent the development of such diseases by blocking only one of these signaling pathways [1]. Recently, it has been revealed that food ingredients exhibit diverse functions that help prevent various diseases associated with biological regulatory system abnormalities. Foods with these actions are known as functional foods. Functional foods with multi-faceted actions are inexpensive and play an important role in increasing healthy life expectancy and improving quality of life [2]. 
Curcumin is a natural polyphenol extracted from the rhizome of Curcuma longa. It has been used as a traditional medicine to treat various diseases, in India and China. Recently, curcumin has received considerable attention owing to its multiple pharmacological activities, such as anti-inflammatory, antioxidant, anti-viral, anti-tumor, and cell protective effects [3-5], and it is expected to be used as a supplement to prevent lifestyle-related diseases [6]. Despite its beneficial effects and low toxicity in humans, the poor water solubility and extremely low bioavailability of curcumin limit its widespread application [7]. Lao et al. reported that the maximum plasma concentration $\left(C_{\max }\right)$ of curcumin was only 50.5 and $57.6 \mathrm{ng} / \mathrm{mL}$ after $10 \mathrm{~g}$ and $12 \mathrm{~g}$ curcumin intake, respectively, in humans [7]. Even if a high dose of curcumin is orally administered, only a small quantity of curcumin is detected in blood plasma. Moreover, curcumin in plasma is rapidly metabolized and excreted in feces and urine [8].

Many studies have been conducted to overcome the limitations of existing curcumin delivery systems, such as particles, micelles, emulsions, and liposomes [9-12]. In our previous study, we prepared an effective curcumin preparation Theracurmin ${ }^{\circledR}$, which is a submicron-particle colloidal dispersion [13]. Theracurmin ${ }^{\circledR}$ achieved a 27 -fold higher area under the plasma concentration-time curve $(A U C)$ at $0-6 \mathrm{~h}$ than native curcumin in humans. The $C_{\max }$ of Theracurmin ${ }^{\circledR}$ was 10.7 - and 5.6 -fold higher than that of the commercial curcumin preparations $\mathrm{BCM}-95 \AA$ and Meriva ${ }^{\circledR}$, respectively [14].

In this study, we prepared a new amorphous solid dispersion of curcumin and named it curcuRouge ${ }^{\mathrm{TM}}$. curcuRouge $^{\mathrm{TM}}$ showed better oral bioavailability than Theracurmin ${ }^{\circledR}$ in rats. Moreover, we determined the oral absorption efficiency of curcuRoug $\mathrm{e}^{\mathrm{TM}}$ and compared it with that of Theracurmin ${ }^{\circledR}$ by performing a randomized, double-blind, two-way crossover clinical study in healthy volunteers.

\section{Materials And Methods}

\section{Chemicals}

Native curcumin, mepronil, $\beta$-glucuronidase, and chloroform were purchased from Wako (Osaka, Japan). Theracurmin ${ }^{\circledR}$ was purchased from a market.

\section{Preparation of curcuRouge ${ }^{\mathrm{m}}$}

curcuRouge $^{\text {TM }}$ was prepared and supplied by Therabiopharma Inc. Briefly, curcumin was amorphized by heating, coarsely ground, and then mixed with a dispersant to produce a fine powder. X-ray diffraction (XRD) analysis was performed using a MiniFlex diffractometer (Rigaku Co., Japan). Microscopic images were taken using a Primovert inverted microscope (Zeiss, Deutschland).

\section{Experimental design in rats}

The animal experiment conformed to the Guide for the Care and Use of Laboratory Animals by the Institute of Laboratory Animals, University of Shizuoka (US\#176279). 
The experiment was performed according to a previous study (15). Briefly, 10 male Sprague-Dawley rats (8-week-old; $250-290 \mathrm{~g})$ were randomly assigned to the Theracurmin ${ }^{\circledR}(N=5)$ and curcuRouge ${ }^{\mathrm{TM}}(\mathrm{N}=5)$ groups. The curcumin preparations were orally administered at a dose of $10 \mathrm{mg} / \mathrm{kg}$ through direct stomach intubation using a sonde. Blood samples were collected from the tail of rats at $0,0.25,0.5,1,2$, 4 , and $6 \mathrm{~h}$ after administration; then, placed in dark-colored heparinized tubes to protect from light, centrifuged at $1,500 \times \mathrm{g}$ for $10 \mathrm{~min}$, and stored at $-20^{\circ} \mathrm{C}$ until analysis.

\section{Clinical study in humans}

The clinical study was approved by the Clinical Research Ethics Committees of Shizuoka General Hospital (SGHIRB\#2019071), University of Shizuoka (IRB\#1-25), and Kyoto Medical Center (IRB\#19056). The study was conducted in accordance with the ethical principles based on the Helsinki Declaration, and it was registered with the UMIN Clinical Trials Registry (UMIN000039083). This singledose, double-blind, two-way crossover study was performed from 8 January 2020 to 2 February 2020 at Shizuoka General Hospital and the University of Shizuoka in Japan. All volunteers provided written informed consent prior to participation in compliance with the Declaration of Helsinki. Twelve healthy volunteers were enrolled in the study. The screening procedures included medical history examination, physical examination, hematologic profiling, and blood chemistry analysis. The volunteers were not taking any medications or any dietary or herbal supplements. Women who were pregnant or breastfeeding were excluded from the study.

The clinical study was performed according to a previous study (16). The participants were divided into two groups. The components of Theracurmin ${ }^{\circledR}$ and curcuRouge ${ }^{\mathrm{TM}}$ are shown in Table 1. Both the preparations were labeled; however, the volunteers and researchers were blinded to the preparations. The volunteers did not consume curcumin-containing food for more than one week before this study. The day before the study, they finished dinner by 9 PM, and fasted overnight (water intake was not restricted). The next morning, the volunteers consumed either of the curcumin preparations (90 $\mathrm{mg}$ ) with a sip of mineral water. Blood specimens were collected immediately before and at $0.5,1,2,4$, and $8 \mathrm{~h}$ after taking the preparations. After blood sampling at $4 \mathrm{~h}$, the volunteers were fed a rice ball containing pickled plum for lunch. All blood specimens were collected in $5 \mathrm{~mL}$ blood-collecting vessels containing heparin, immediately centrifuged at $1,500 \times \mathrm{g}$ for $10 \mathrm{~min}$, and stored at $-20^{\circ} \mathrm{C}$ until analysis. After a washout period of 1-2 weeks, the alternate curcumin preparation was administered using the same protocol. After the measurement of plasma curcumin concentration, these data were fixed, and the labels were opened.

\section{Power analysis}

Power analysis was performed using G*Power 3.1.9.2 software [17]. A previous crossover study examined the effects of Theracurmin ${ }^{\circledR}$ in nine healthy volunteers (dropout rate: $0 \%$ ) $[14,16]$. Based on the results of that study, a power analysis was performed with an effective dose of 0.5 , a power of 0.7 , and a significance level of 0.05 . Assuming a dropout rate of $5 \%$, the sample size for the current study was determined as 12 volunteers. 


\section{Sample preparation and measurement of plasma curcumin levels}

The measurement of plasma curcumin levels was performed as reported previously [13]. Briefly, each plasma sample was reacted with $1,000 \cup \beta$-glucuronidase at $37^{\circ} \mathrm{C}$ for $1 \mathrm{~h}$ to hydrolyze the curcumin conjugates. After extraction with chloroform, the dried extracts were reconstituted in $50 \%$ acetonitrile and injected into an HPLC-MS/MS system comprising the Elute UHPLC system (Bruker Japan, Japan) and micrOTOF compact (Bruker Japan, Japan) with (+) electrospray ionization.

\section{Pharmacokinetics}

The $A U C$ was calculated using the trapezoidal method [13]. The $C_{\max }$ and time to reach maximum concentration $\left(T_{\max }\right)$ were obtained directly from the measured data. The relative values among native curcumin, Theracurmin ${ }^{\circledR}$, and curcuRoug $\mathrm{e}^{\mathrm{TM}}$ were calculated using individual data, and the mean values were then represented.

\section{Statistical analysis}

Data are expressed as the mean \pm standard deviation (S.D.). For evaluation of curcumin absorption, nonparametric Kruskal-Wallis test followed by the Steel-Dwass test was performed. $p<0.05$ was considered statistically significant.

\section{Results}

\section{XRD analysis and microscope images of curcuRouge ${ }^{\mathrm{TM}}$}

The physical formulation of curcuRouge ${ }^{T M}$ was characterized using the XRD system. As can be seen in Fig. 1, the XRD pattern of native curcumin showed several intense peaks, which indicated crystal forms of curcumin. In contrast, the XRD pattern of curcuRouge ${ }^{\text {TM }}$ showed a typical halo form without characteristic peaks. The photographic images of native curcumin and curcuRouge ${ }^{\mathrm{TM}}$ are shown in Fig. 2. Native curcumin is yellow in color, whereas curcuRouge ${ }^{\text {TM }}$ has a light red shade (Fig. 2A and 2B). Small particles of curcumin $(<10 \mu \mathrm{m})$ were observed in curcuRouge ${ }^{\mathrm{TM}}$ (Fig. 2C). These data indicated that curcuRouge ${ }^{\mathrm{TM}}$ is an amorphous formulation.

\section{Bioavailability of curcuRouge $^{\mathrm{m}}$ and Theracurmin ${ }^{\circledR}$ in rats}

The curcumin concentrations in plasma at $0,0.25,0.5,1,2,4$, and $6 \mathrm{~h}$ are shown in Fig. 3. The serum concentration of curcumin was significantly higher until $4 \mathrm{~h}$ in rats administered curcuRouge ${ }^{\mathrm{TM}}$ than in those administered Theracurmin ${ }^{\circledR}$. The pharmacokinetic parameters, including $C_{\max }, T_{\max }$, and $A U C$, are presented in Table 2. The $C_{\max }$ values of curcuRouge $^{\mathrm{TM}}$ and Theracurmin ${ }^{\circledR}$ were $970 \pm 139$ and $104 \pm$ $18 \mathrm{ng} / \mathrm{mL}$, respectively $(p<0.01)$. The $T_{\max }$ of curcuRouge ${ }^{T M}(0.25 \pm 0.00 \mathrm{~h}, p<0.01)$ was significantly shorter than that of Theracurmin ${ }^{\circledR}(0.60 \pm 0.20 \mathrm{~h})$. The $A U C_{0-0.5 \mathrm{~h}}$ and $A U C_{0-6} \mathrm{~h}$ were $321 \pm 42$ and 1089 $\pm 343 \mathrm{ng} / \mathrm{mL}$, respectively, for curcuRouge ${ }^{\mathrm{Tm}}$ and $30 \pm 4$ and $296 \pm 63 \mathrm{ng} / \mathrm{mL}$, respectively, for 
Theracurmin ${ }^{\circledR}$. These results indicated that curcuRouge ${ }^{\mathrm{TM}}$ achieved $C_{\mathrm{max}}$ in a shorter time. The $C_{\max }$ of curcuRouge ${ }^{\text {TM }}$ was 9.6 -fold higher than that of Theracurmin ${ }^{\circledR}$. Moreover, the bioavailability of curcuRouge ${ }^{\mathrm{TM}}$ was 3.7-fold higher than that of Theracurmin ${ }^{\circledR}$.

\section{Volunteer characteristics and disposition}

Twelve healthy volunteers (eight men and four women) were enrolled in this study; their mean age was $22.8 \pm 2.1$ years. The mean body mass index was $20.9 \pm 2.0 \mathrm{~kg} / \mathrm{mm}^{2}$. The hemodynamic and blood analysis parameters are presented in Table 3. No volunteer discontinued the study, and no adverse effects were observed during this study.

\section{Bioavailability of curcuRouge ${ }^{\mathrm{m}}$ and Theracurmin ${ }^{\circledR}$ in humans}

The plasma curcumin concentrations at $0,0.5,1,2,4$, and $8 \mathrm{~h}$ are shown in Fig. 4 . curcuRouge ${ }^{\mathrm{TM}}$ exhibited significantly higher plasma curcumin levels at $0.5,1,2$, and $4 \mathrm{~h}$ than Theracurmin $\circledast$. The pharmacokinetic parameters are presented in Table 3 . The $C_{\max }$ of curcuRouge ${ }^{\mathrm{TM}}(493 \pm 352 \mathrm{ng} / \mathrm{mL}, p<0.001)$ was 5.4 -fold higher than that of Theracurmin ${ }^{\circledR}(92 \pm 52 \mathrm{ng} \mathrm{mL})$. The $T_{\max }$ was significantly shorter in the curcuRouge $^{\text {TM }}$ group $(2.0 \pm 1.5 \mathrm{~h}, p<0.05)$ than in the Theracurmin ${ }^{\circledR}$ group $(5.3 \pm 3.1 \mathrm{~h})$. The $A U C_{0-0.5 \mathrm{~h}}$ and $A U C_{0-8 \mathrm{~h}}$ of curcuRouge ${ }^{\mathrm{Tm}}(76 \pm 83 \mathrm{ng} / \mathrm{mL}, p<0.01$ and $1552 \pm 948 \mathrm{ng} / \mathrm{mL}, p<0.01)$ was 30.6- and 3.4-fold higher than those of Theracurmin ${ }^{\circledR}(2 \pm 3$ and $458 \pm 287 \mathrm{ng} / \mathrm{mL}$, respectively). These results indicated that curcuRouge ${ }^{\text {TM }}$ could achieve the $C_{\max }$ in a shorter time than Theracurmin ${ }^{\circledR}$ in humans as well as rats. In humans, the bioavailability of curcuRouge ${ }^{\mathrm{Tm}}$ (based on the $C_{\max }$ and $A U C$ values) significantly improved compared with that of Theracurmin ${ }^{\circledR}$.

\section{Discussion}

In this study, we developed curcuRouge ${ }^{\mathrm{TM}}$, an amorphous curcumin preparation, to improve the oral absorption of curcumin. Oral absorption experiments in rats showed that the $C_{\text {max }}$ and $A U C_{0-6 \mathrm{~h}}$ of curcuRouge ${ }^{\text {TM }}$ were 9.6- and 3.7-fold higher than those of Theracurmin ${ }^{\circledR}$, respectively. The crossover study comparing the oral absorption of Theracurmin ${ }^{\circledR}$ and curcuRoug $\mathrm{e}^{\mathrm{TM}}$ in healthy volunteers revealed that the $C_{\text {max }}$ and $A U C_{0-8 \mathrm{~h}}$ of curcuRouge ${ }^{\mathrm{TM}}$ were 5.4- and 3.4-fold higher than those of Theracurmin ${ }^{\circledR}$, respectively. These results demonstrated that the novel curcumin preparation curcuRouge ${ }^{\mathrm{TM}}$ exhibited more than 3-fold higher oral absorption and bioavailability than Theracurmin ${ }^{\circledR}$.

Curcumin has been expected to be applied for the prevention of various diseases [18, 19]. Currently, some of the highly absorbed curcumin preparations are commercially available and being applied clinically to address the poor oral absorption of curcumin. Meriva ${ }^{\circledR}$ is a mixture of curcumin and phosphatidylcholine derived from soybean lecithin and contains $20 \%$ curcuminoids [20]. It has been shown to have 29 times higher absorption than curcumin. Longvida ${ }^{\circledR}$ is also a solid lipid curcumin particle-based formulation with soy lecithin containing purified phospholipids [21]. A comparative pharmacokinetic study in healthy 
volunteers demonstrated that the bioavailability of Longvida ${ }^{\circledR}$ is 100 times higher than that of curcuminoids ( $A U C_{0-\mathrm{t}}: 95.3 \mathrm{ng} \cdot \mathrm{h} / \mathrm{mL} / 650 \mathrm{mg}$ curcuminoids). BCM-95® is a mixture of curcumin and turmeric-derived essential oils, and its bioavailability has been shown to be 6.9 times higher than that of curcumin [22]. CurcuWin ${ }^{\circledR}$ is a water-soluble formulation comprising polyvinyl pyrrolidine as a hydrophilic carrier, cellulosic derivatives, and natural antioxidants [23]. The relative absorption of curcumin in CurcuWin ${ }^{\circledR}$ is 136 times higher than that of curcumin $\left(A U C_{0-12} \mathrm{~h}: 307 \mathrm{ng} \cdot \mathrm{h} / \mathrm{mL} / 376 \mathrm{mg}\right.$ curcuminoids). NovaSol® is a micelle formulation with Tween-80 as a nonionic surfactant [24]. Its bioavailability is 185 times higher than that of unformulated curcumin. These preparations have demonstrated superior oral absorption to native curcumin in humans; however, these studies used high doses of curcumin formulation (300-2000 mg). A high plasma level of curcumin may cause for potential adverse effects. Thus, a comparative study using a low dose should be performed to determine the effective and optimal blood levels of curcumin that do not pose any risks. Theracurmin $\AA$, which we developed previously, showed 27-fold higher oral absorption than native curcumin in humans at a dose of $30 \mathrm{mg}$ curcumin equivalent, which is lower than the doses reported in other clinical studies [13]. A comparison among Theracurmin $\AA$ and the existing preparations Meriva $\AA$ and BCM- $95 \AA$ demonstrated that Theracurmin ${ }^{\circledR}$ had the highest oral absorption [14]. To develop a curcumin preparation with improved absorption efficiency at a low dose when compared with Theracurmin ${ }^{\circledR}$, we prepared amorphous curcumin. Generally, the bioavailability and stability of poorly water-soluble drugs is improved in their amorphous forms [25]. curcuRouge ${ }^{\mathrm{TM}}$ particles were approximately $<10 \mu \mathrm{m}$ in diameter, and XRD revealed that they are amorphous. The results of animal and human studies showed that the amorphous form of curcuRouge ${ }^{\text {TM }}$ had $>3$-fold higher oral absorption than Theracurmin ${ }^{\circledR}$. The amorphous form of curcuRouge $^{\text {TM }}$ is considered to contribute to its improved bioavailability. Comparison of curcuRouge ${ }^{T M}$ with other types of curcumin formulations was difficult because the clinical study conditions were different. However, our findings suggest that curcuRouge ${ }^{\text {TM }}$ possesses higher bioavailability than Theracurmin ${ }^{\circledR}$.

Curcumin preparations with improved absorption characteristics can help exert the beneficial physiological effects of curcumin. To date, highly absorbed curcumin preparations have been demonstrated to have the following effects on various illnesses: improved QOL in patients with end-stage pancreatic cancer [26]; improved memory function and reduced amyloid- $\beta /$ tau protein accumulation in patients with mild cognitive impairment [27]; improvement of moderate Crohn's disease [28]; alleviation of pain in patients with knee osteoarthritis [29-31]; and decreased levels of a1-antitrypsin-LDL, a form of oxidized LDL in blood, and possible reduction of cardiovascular risk in patients with moderate chronic obstructive pulmonary disease [32]. Many animal experiments have revealed the potential of curcumin as a therapeutic agent for hypertension and myocardial infarction-induced heart diseases [33, 34], diabetes [35], obesity [36], and atherosclerosis [37]. curcuRouge ${ }^{\mathrm{TM}}$ developed in this study is considered to have a higher bioavailability than Theracurmin $\AA$ and other absorption-improved preparations, such as BCM- $95 \AA$ and Meriva ${ }^{\circledR}$. Our findings suggest that curcuRoug ${ }^{\mathrm{Tm}}$ as well as other highly absorbed preparations have the potential to demonstrate beneficial effects in patients with the abovementioned diseases even at low doses. 
As curcuRouge ${ }^{T M}$ can readily reach high blood levels that native curcumin cannot, adverse reactions that have previously remained unnoticed may emerge. To confirm the safety of curcuRouge ${ }^{\mathrm{TM}}$, we conducted a 28-day repeated dose safety study of $300 \mathrm{mg} / \mathrm{kg}$ curcumin in rats. The results indicated that repeated administration of curcuRouge ${ }^{\mathrm{TM}}$ at a high dose caused no abnormalities in general well-being and findings from observing internal organs after autopsy (Additional file 1). No adverse reactions occurred in humans after a single administration of curcuRouge ${ }^{\mathrm{TM}}$ (90 mg curcumin) in this study. However, additional careful investigation of adverse reactions is necessary for its clinical application.

\section{Conclusion}

In this study, we demonstrated that the amorphous form of curcuRouge ${ }^{T M}$ had superior oral absorption to Theracurmin $\circledast$ in rats and humans. Therefore, this novel curcumin preparation can effectively exert the physiological activities of curcumin at low doses. CurcuRouge ${ }^{\mathrm{TM}}$ is expected to be used as a highly functional food material for managing various diseases, including lifestyle diseases.

\section{List Of Abbreviations}

AUC: Area Under the plasma Concentration-time curve

Cmax: plasma maximum Concentration

UMIN: University hospital Medical Information Network

QOL: Quality Of Life

ASD: Amorphous Solid Dispersion

XRD: X-ray diffraction

SD: Sprague-Dawley

HPLC-MS/MS: Liquid Chromatography / Mass Spectrometry

UHPLC: Ultra High Performance Liquid Chromatography

SD: standard deviation

BMl: Body-Mass Index

\section{Declarations}

\section{Authors' contributions}


Yoichi Sunagawa and Tatsuya Morimoto designed this study. Yusuke Miyazaki, Masafumi Funamoto, Kana Shimizu, and Satoshi Shimizu conducted clinical research. Koji Hasegawa provided essential advice for clinical research. Nurmila Sari and Yasufumi Katanasaka analyzed the data and performed statistical analysis. Masashi Ito, Tatsuya Ogawa, and Hitomi Ozawa-Umeta performed the animal experiment, measured plasma curcumin levels, and provided curcuRouge ${ }^{\mathrm{TM}}$. Yoichi Sunagawa, Koji Hasegawa, and Tatsuya Morimoto wrote the manuscript. Tatsuya Morimoto had the primary responsibility for determining the final content. All authors have read and approved the final manuscript.

\section{Acknowledgments}

We thank Yusaku Matsushita, Mizuki Unno, Hiroko Mochizuki, Yuko Iwasaki, and Eriko Morimoto for their technical assistance. We would like to thank Editage (www.editage.com) for English language editing.

\section{Funding}

This work was supported by a grant from the Japan Science and Technology Agency (T. Morimoto; 17K08279, Hasegawa; 18K08121) and joint research funding from Therabiopharma Inc.

\section{Availability of data and materials}

The datasets used and/or analyzed during the current study are available from the corresponding author on reasonable request.

\section{Ethics approval and consent to participate}

This study was approved by the Clinical Research Ethics Committees of Shizuoka General Hospital (SGHIRB\#2019071), University of Shizuoka (IRB\#1-25), and Kyoto Medical Center (IRB\#19-056), conducted in accordance with the ethical principles based on the Helsinki Declaration. The study was registered with the UMIN Clinical Trials Registry (UMIN000039083). Written informed consent was obtained from all participants.

\section{Consent for publication}

Not applicable.

\section{Competing interests}

Yoichi Sunagawa, Yusuke Miyazaki, Masafumi Funamoto, Kana Shimizu, Satoshi Shimizu, Sari Nurmila, Yasufumi Katanasaka, Koji Hasegawa, and Tatsuya Morimoto declare that they have no competing interests. Masashi Ito, Tatsuya Ogawa, and Hitomi Ozawa-Umeta are employees of Therabiopharma Inc.

\section{References}

1. Simon Frantz. Drug discovery: Playing dirty. Nature. 2005;437:942-943. 
2. Koeberle A, Werz O. Multi-target approach for natural products in inflammation. Drug Discov Today. 2014;19:1871-1882.

3. Khan $\mathrm{H}$, Ullah H, Nabavi SM. Mechanistic insights of hepatoprotective effects of curcumin: Therapeutic updates and future prospects. Food Chem Toxicol. 2019;124:182-191.

4. Deguchi A. Curcumin targets in inflammation and cancer. Endocr Metab Immune Disord Drug Targets. 2015;15:88-96.

5. Farhood B, Mortezaee K, Goradel NH, Khanlarkhani N, Salehi E, Nashtaei MS, Najafi M, Sahebkar A. Curcumin as an anti-inflammatory agent: Implications to radiotherapy and chemotherapy. J Cell Physiol. 2019;234:5728-5740.

6. Salehi B, Stojanović-Radić Z, Matejić J, Sharifi-Rad M, Anil Kumar NV, Martins N, Sharifi-Rad J. The therapeutic potential of curcumin: A review of clinical trials. Eur J Med Chem. 2019;163:527-545.

7. Lao CD, Ruffin MT 4th, Normolle D, Heath DD, Murray SI, Bailey JM, Boggs ME, Crowell J, Rock CL, Brenner DE. Dose escalation of a curcuminoid formulation. BMC Complement Altern Med. 2006;6:10.

8. Niu Y, Ke D, Yang Q, Wang X, Chen Z, An X, Shen W. Temperature-dependent stability and DPPH scavenging activity of liposomal curcumin at pH 7.0. Food Chem. 2012;135:1377-1382.

9. Feng T, Wei Y, Lee RJ, Zhao L. Liposomal curcumin and its application in cancer. Int J Nanomedicine. 2017;12:6027-6044.

10. Chebl M, Moussa Z, Peurla M, Patra D. Polyelectrolyte mediated nano hybrid particle as a nanosensor with outstandingly amplified specificity and sensitivity for enzyme free estimation of cholesterol. Talanta. 2017;169:104-114.

11. Guerrero S , Inostroza-Riquelme M , Contreras-Orellana P , Diaz-Garcia V , Lara P, Vivanco-Palma A, Cárdenas A, Miranda V , Robert P, Leyton L, Kogan MJ , Quest AFG , Oyarzun-Ampuero F . Curcumin-loaded nanoemulsion: a new safe and effective formulation to prevent tumor reincidence and metastasis. Nanoscale. 2018;10:22612-22622.

12. Tan X, Kim G , Lee D , Oh J , Kim M , Piao C , Lee J , Lee MS , Jeong JH, Lee M . A curcumin-loaded polymeric micelle as a carrier of a microRNA-21 antisense-oligonucleotide for enhanced anti-tumor effects in a glioblastoma animal model. Biomater Sci. 2018;6:407-417.

13. Sasaki H, Sunagawa Y, Takahashi K, Imaizumi A, Fukuda H, Hashimoto T, Wada H, Katanasaka Y, Kakeya H, Fujita M, Hasegawa K, Morimoto T. Innovative preparation of curcumin for improved oral bioavailability. Biol Pharm Bull. 2011;34:660-665.

14. Sunagawa Y, Hirano S, Katanasaka Y, Miyazaki Y, Funamoto M, Okamura N, Hojo Y, Suzuki H, Doi O, Yokoji T, Morimoto E, Takashi T, Ozawa H, Imaizumi A, Ueno M, Kakeya H, Shimatsu A, Wada H, Hasegawa K, Morimoto T. Colloidal submicron-particle curcumin exhibits high absorption efficiency-a double-blind, 3-way crossover study. J Nutr Sci Vitaminol (Tokyo). 2015;61:37-44.

15. Sunagawa $Y$, Wada $H$, Suzuki $H$, Sasaki $H$, Imaizumi A, Fukuda $H$, Hashimoto T, Katanasaka $Y$, Shimatsu A, Kimura T, Kakeya H, Fujita M, Hasegawa K, Morimoto T. A novel drug delivery system of oral curcumin markedly improves efficacy of treatment for heart failure after myocardial infarction in rats. Biol Pharm Bull. 2012;35:139-144. 
16. Morimoto T, Sunagawa Y, Katanasaka Y, Hirano S, Namiki M, Watanabe Y, Suzuki H, Doi O, Suzuki K, Yamauchi M, Yokoji T, Miyoshi-Morimoto E, Otsuka Y, Hamada T, Imaizumi A, Nonaka Y, Fuwa T, Teramoto T, Kakeya H, Wada H, Hasegawa K. Drinkable preparation of Theracurmin exhibits high absorption efficiency--a single-dose, double-blind, 4-way crossover study. Biol Pharm Bull. 2013;36:1708-1714.

17. Faul F, Erdfelder E, Lang AG, Buchner A. G*Power 3: a flexible statistical power analysis program for the social, behavioral, and biomedical sciences. Behav Res Methods. 2007;39:175-191.

18. Sunagawa Y, Katanasaka Y, Hasegawa K, Morimoto T. Clinical applications of curcumin. PharmaNutrition. 2015;3:131-135.

19. Morimoto T, Funamoto M, Sunagawa Y, Katanasaka Y, Miyazaki Y, Hasegawa K. Noble Heart Failure Therapy Using Food Compositions. Yakugaku Zasshi. 2018;138:1263-1269.

20. Cuomo J, Appendino G, Dern AS, Schneider E, McKinnon TP, Brown MJ, Togni S, Dixon BM. Comparative absorption of a standardized curcuminoid mixture and its lecithin formulation. J Nat Prod. 2011;74:664-669.

21. Gota VS, Maru GB, Soni TG, Gandhi TR, Kochar N, Agarwal MG. Safety and pharmacokinetics of a solid lipid curcumin particle formulation in osteosarcoma patients and healthy volunteers. J Agric Food Chem. 2010; 58: 2095-2099.

22. Antony B, Merina B, lyer VS, Judy N, Lennertz K, Joyal S. A Pilot Cross-Over Study to Evaluate Human Oral Bioavailability of BCM-95CG (Biocurcumax), A Novel Bioenhanced Preparation of Curcumin. Indian J Pharm Sci. 2008;70:445-449.

23. Jäger R, Lowery RP, Calvanese AV, Joy JM, Purpura M, Wilson JM. Comparative absorption of curcumin formulations. Nutr J. 2014; 13: 11.

24. Schiborr C, Kocher A, Behnam D, Jandasek J, Toelstede S, Frank J. The oral bioavailability of curcumin from micronized powder and liquid micelles is significantly increased in healthy humans and differs between sexes. Mol Nutr Food Res. 2014 Mar;58(3):516-27.

25. Tran PHL, Duan W, Lee BJ, Tran TTD. Modulation of Drug Crystallization and Molecular Interactions by Additives in Solid Dispersions for Improving Drug Bioavailability. Curr Pharm Des. 2019;25:20992107.

26. Pastorelli D, Fabricio ASC, Giovanis P, D'Ippolito S, Fiduccia P, Soldà C, Buda A, Sperti C, Bardini R, Da Dalt G, Rainato G, Gion M, Ursini F. Phytosome complex of curcumin as complementary therapy of advanced pancreatic cancer improves safety and efficacy of gemcitabine: Results of a prospective phase II trial. Pharmacol Res. 2018;132:72-79.

27. Small GW, Siddarth P, Li Z, Miller KJ, Ercoli L, Emerson ND, Martinez J, Wong KP, Liu J, Merrill DA, Chen ST, Henning SM, Satyamurthy N, Huang SC, Heber D, Barrio JR. Memory and Brain Amyloid and Tau Effects of a Bioavailable Form of Curcumin in Non-Demented Adults: A Double-Blind, PlaceboControlled 18-Month Trial. Am J Geriatr Psychiatry. 2018;26:266-277.

28. Sugimoto K, Ikeya K, Bamba S, Andoh A, Yamasaki H, Mitsuyama K, Nasuno M, Tanaka H, Matsuura A, Kato M, Ishida N, Tamura S, Takano R, Tani S, Osawa S, Nishihira J, Hanai H. Highly bioavailable 
curcumin derivative ameliorates Crohn's disease symptoms: A randomized, double-blind, multicenter study. J Crohns Colitis. 2020:jjaa097.

29. Nakagawa Y, Mukai S, Yamada S, Matsuoka M, Tarumi E, Hashimoto T, Tamura C, Imaizumi A, Nishihira J, Nakamura T. Short-term effects of highly-bioavailable curcumin for treating knee osteoarthritis: a randomized, double-blind, placebo-controlled prospective study. J Orthop Sci. 2014;19:933-9.

30. Shep D, Khanwelkar C, Gade P, Karad S. Efficacy and safety of combination of curcuminoid complex and diclofenac versus diclofenac in knee osteoarthritis: A randomized trial. Medicine (Baltimore). 2020;99:e19723.

31. Belcaro G, Cesarone MR, Dugall M, Pellegrini L, Ledda A, Grossi MG, Togni S, Appendino G. Productevaluation registry of Meriva ${ }^{\circledR}$, a curcumin-phosphatidylcholine complex, for the complementary management of osteoarthritis. Panminerva Med. 2010;52:55-62.

32. Funamoto $M$, Sunagawa $Y$, Katanasaka Y, Miyazaki Y, Imaizumi A, Kakeya H, Yamakage H, SatohAsahara N, Komiyama M, Wada H, Hasegawa K, Morimoto T. Highly absorptive curcumin reduces serum atherosclerotic low-density lipoprotein levels in patients with mild COPD. Int J Chron Obstruct Pulmon Dis. 2016;11:2029-2034.

33. Sunagawa Y, Morimoto T, Wada H, Takaya T, Katanasaka Y, Kawamura T, Yanagi S, Marui A, Sakata R, Shimatsu A, Kimura T, Kakeya H, Fujita M, Hasegawa K. A natural p300-specific histone acetyltransferase inhibitor, curcumin, in addition to angiotensin-converting enzyme inhibitor, exerts beneficial effects on left ventricular systolic function after myocardial infarction in rats. Circ J. 2011;75:2151-2159.

34. Morimoto T, Sunagawa Y, Kawamura T, Takaya T, Wada H, Nagasawa A, Komeda M, Fujita M, Shimatsu A, Kita T, Hasegawa K. The dietary compound curcumin inhibits p300 histone acetyltransferase activity and prevents heart failure in rats. J Clin Invest. 2008; 118: 868-878.

35. Den Hartogh DJ, Gabriel A, Tsiani E. Antidiabetic Properties of Curcumin II: Evidence from In Vivo Studies. Nutrients. 2019;12:58.

36. Kim Y, Rouse M, González-Mariscal I, Egan JM, O'Connell JF. Dietary curcumin enhances insulin clearance in diet-induced obese mice via regulation of hepatic PI3K-AKT axis and IDE, and preservation of islet integrity. Nutr Metab (Lond). 2019;16:48.

37. Zhang S, Zou J, Li P, Zheng X, Feng D. Curcumin Protects against Atherosclerosis in Apolipoprotein EKnockout Mice by Inhibiting Toll-like Receptor 4 Expression. J Agric Food Chem. 2018;66:449-456.

\section{Tables}

Due to technical limitations, table $1,2,3,4$ is only available as a download in the Supplemental Files section.

\section{Figures}




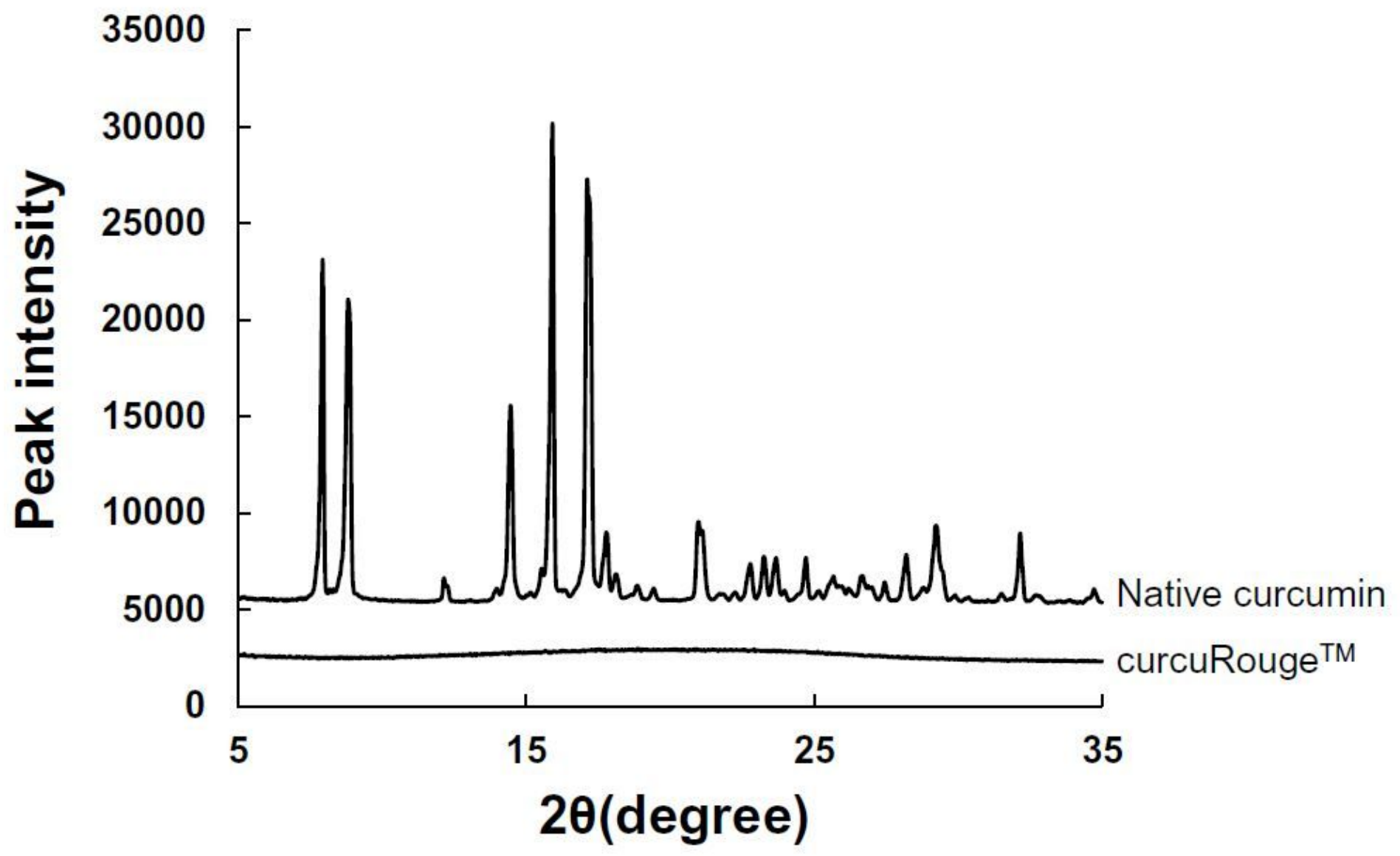

Figure 1

X-ray diffraction patterns of curcuRouge ${ }^{\mathrm{T} M}$ and native curcumin 


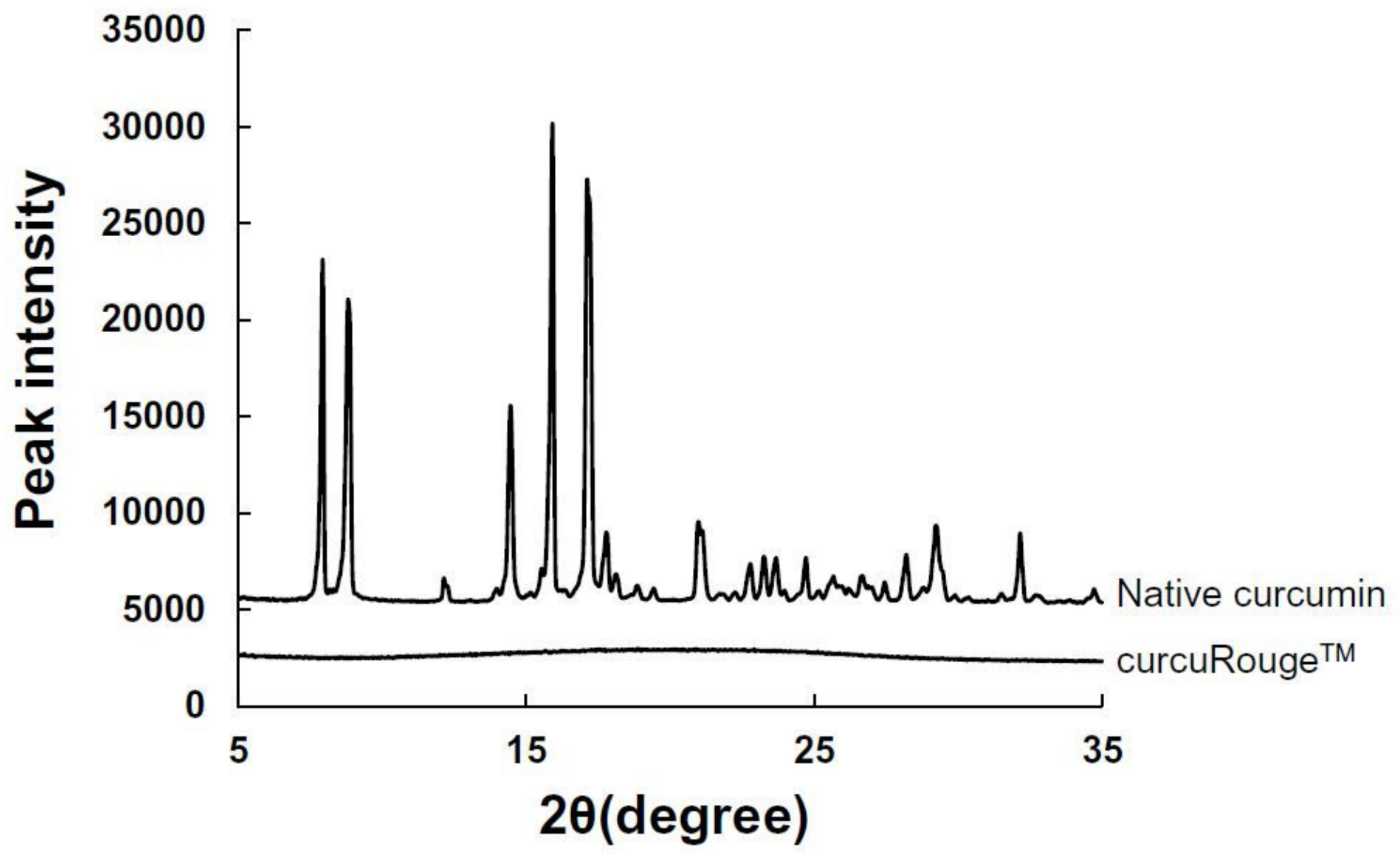

Figure 1

X-ray diffraction patterns of curcuRouge ${ }^{\mathrm{T} M}$ and native curcumin 
A

B
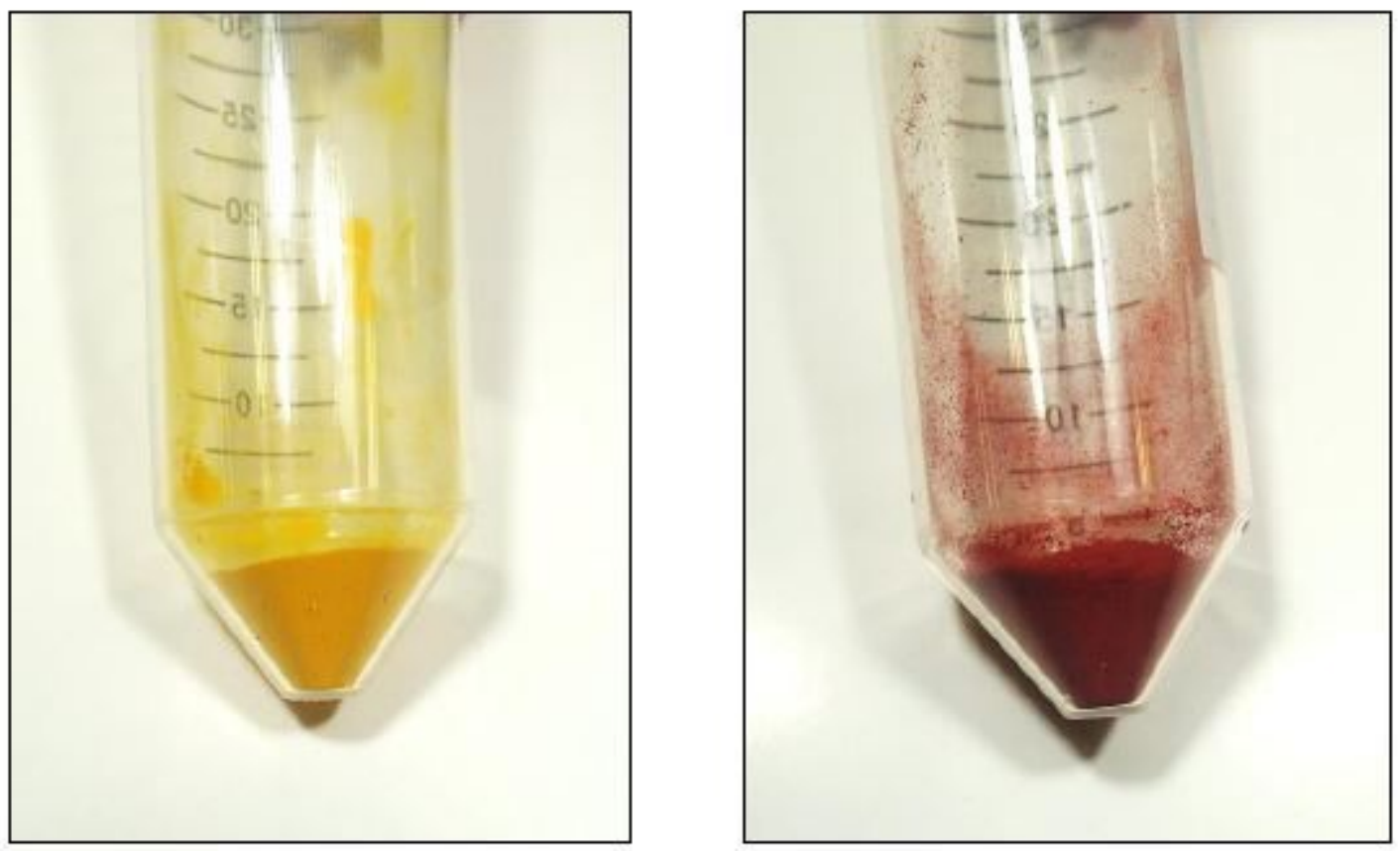

C

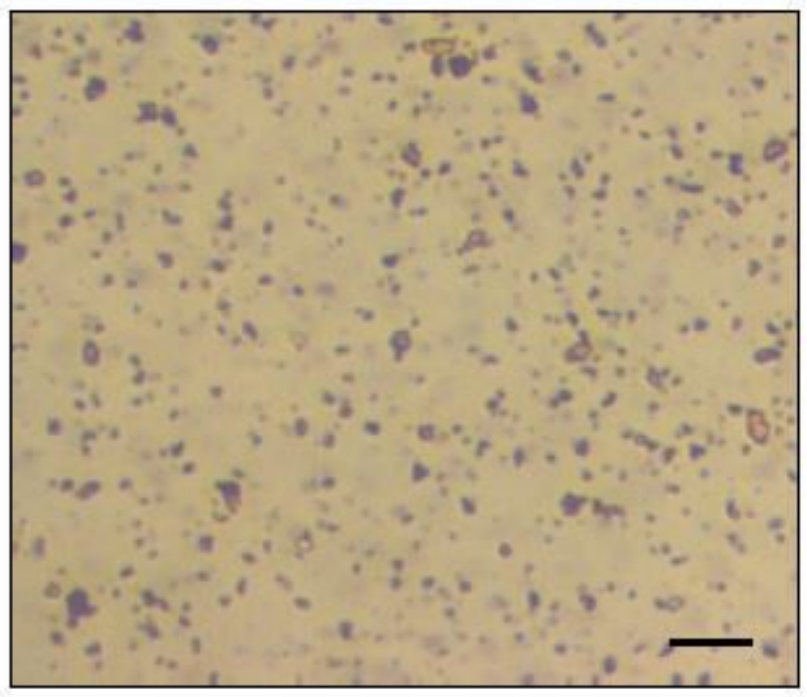

Figure 2

Photographic images of curcuRouge ${ }^{T M}$ Photographic images of native curcumin $(A)$ and curcuRougeTM (B). (C) Light microscope image of curcuRouge ${ }^{\mathrm{TM}}$. The scale bar is $20 \mu \mathrm{m}$. 
A

B
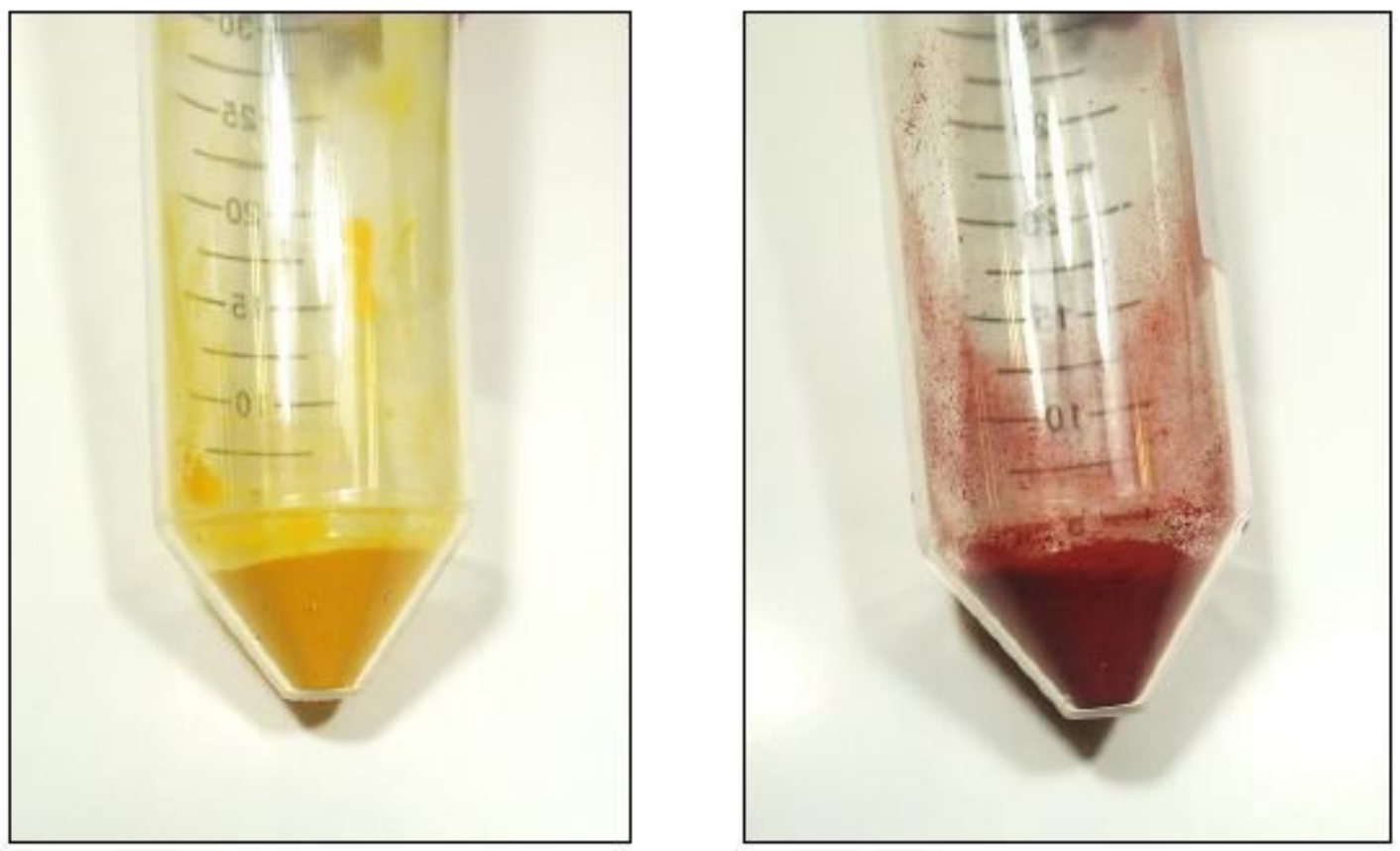

C

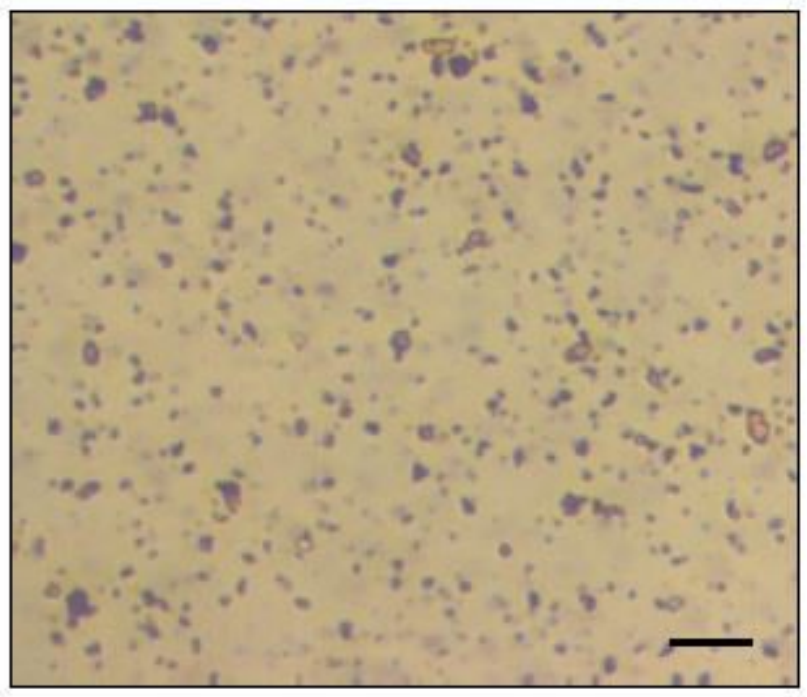

Figure 2

Photographic images of curcuRouge ${ }^{T M}$ Photographic images of native curcumin $(A)$ and curcuRougeTM (B). (C) Light microscope image of curcuRouge ${ }^{\mathrm{TM}}$. The scale bar is $20 \mu \mathrm{m}$. 


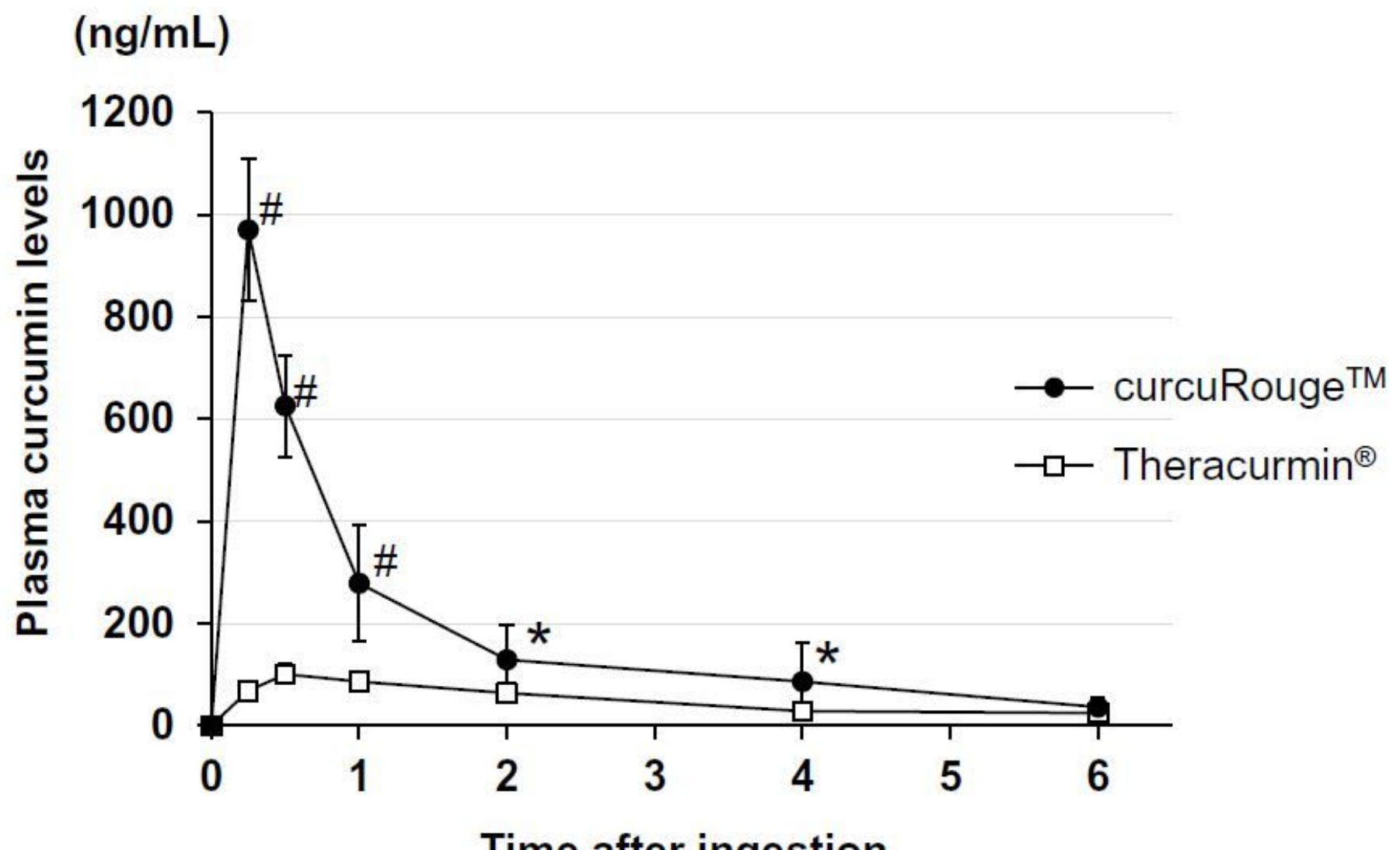

Time after ingestion

Figure 3

Changes in plasma curcumin levels in rats The curcumin levels in plasma at $0,0.5,1,2,4$, and $6 \mathrm{~h}$ after administration of $10 \mathrm{mg} / \mathrm{kg}$ curcumin preparations are graphically presented. Black circle: curcuRouge ${ }^{\mathrm{TM}}$; White square: Theracurmin ${ }^{\circledR}$. Each point and bar represent the mean \pm standard deviation (S.D.) $(n=5)$. 


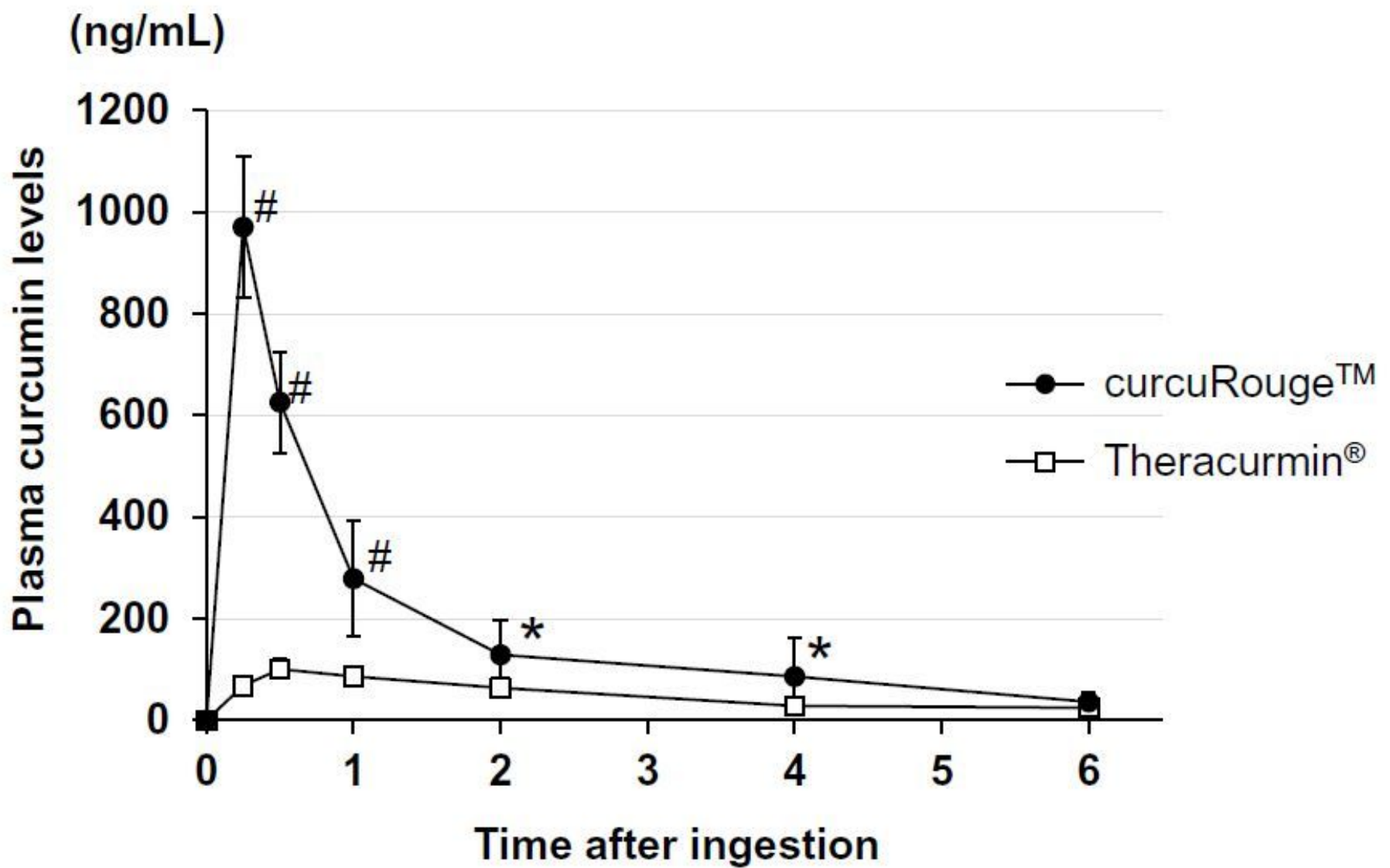

Figure 3

Changes in plasma curcumin levels in rats The curcumin levels in plasma at $0,0.5,1,2,4$, and $6 \mathrm{~h}$ after administration of $10 \mathrm{mg} / \mathrm{kg}$ curcumin preparations are graphically presented. Black circle: curcuRouge ${ }^{\mathrm{TM}}$; White square: Theracurmin ${ }^{\circledR}$. Each point and bar represent the mean \pm standard deviation (S.D.) $(n=5)$. 


\section{(ng/mL)}

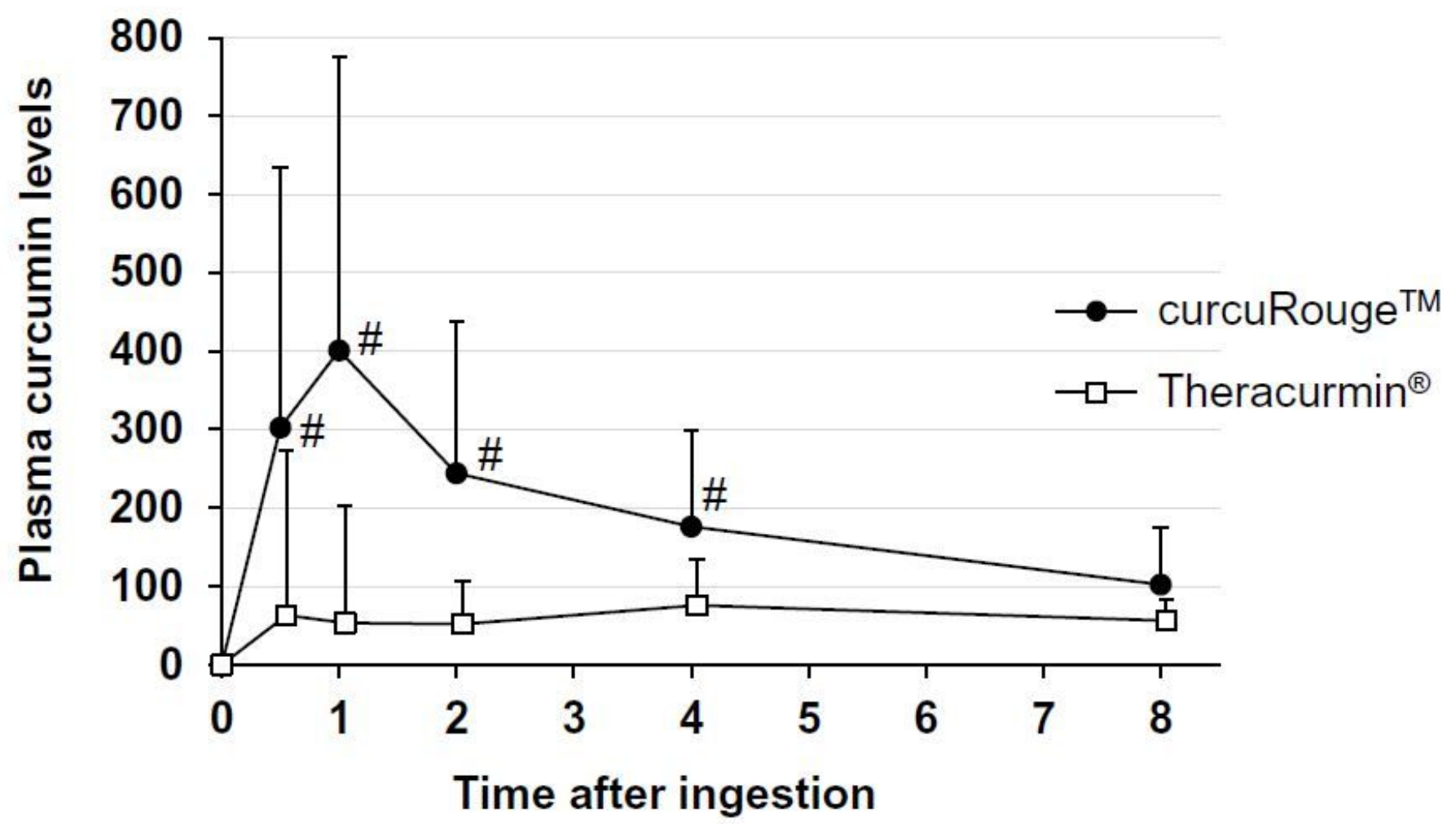

Figure 4

Changes in plasma curcumin levels in healthy volunteers The curcumin levels in plasma at $0,0.5,1,2,4$, and $8 \mathrm{~h}$ after administration of $90 \mathrm{mg}$ curcumin preparations are graphically presented. Black circle:

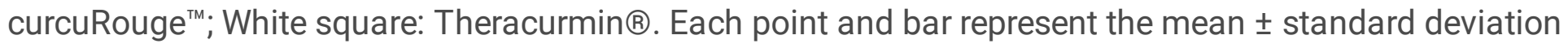
(S.D.) $(n=12)$. 


\section{(ng/mL)}

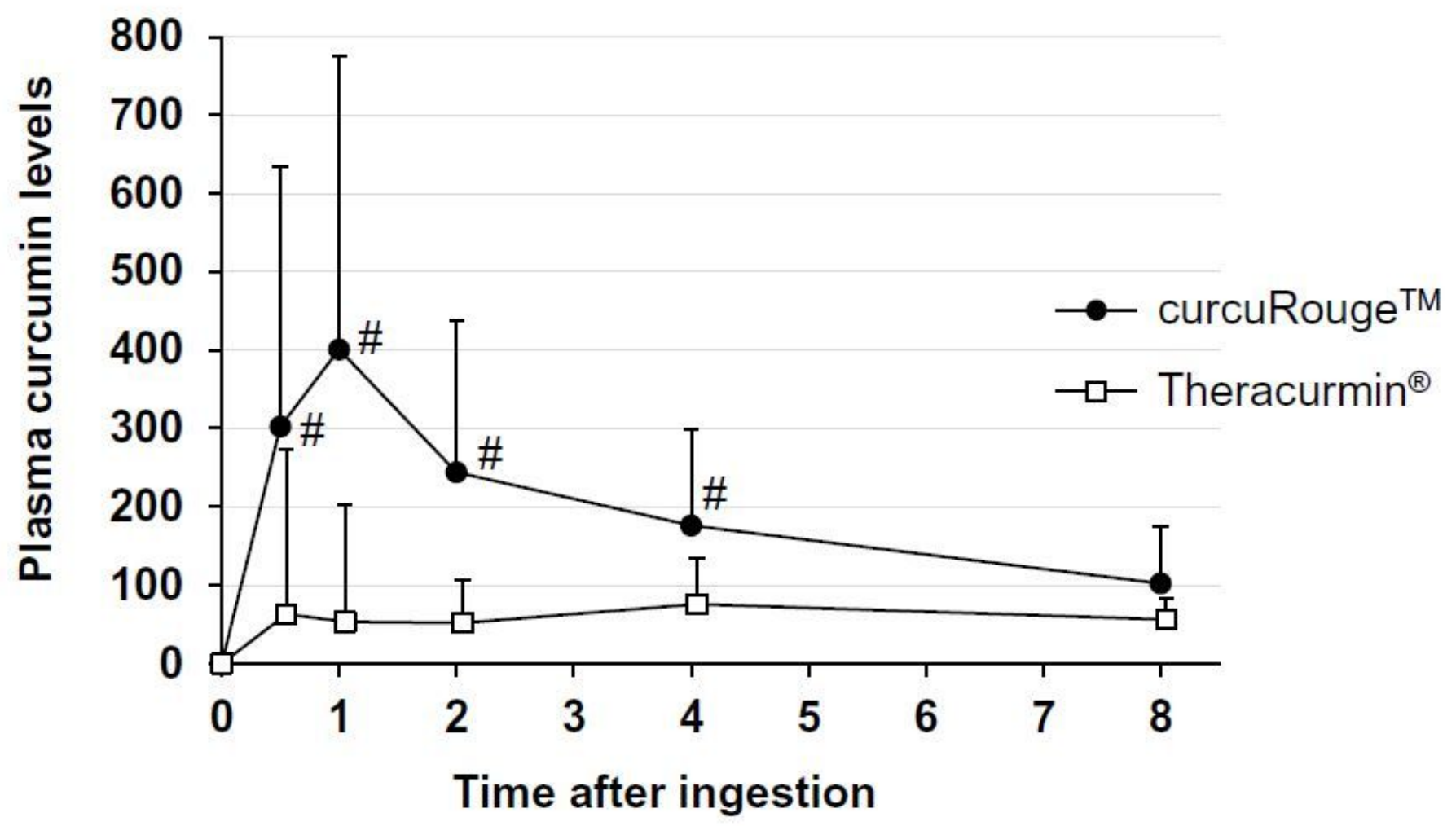

Figure 4

Changes in plasma curcumin levels in healthy volunteers The curcumin levels in plasma at $0,0.5,1,2,4$, and $8 \mathrm{~h}$ after administration of $90 \mathrm{mg}$ curcumin preparations are graphically presented. Black circle: curcuRouge $^{\mathrm{T}}$; White square: Theracurmin ${ }^{\circledR}$. Each point and bar represent the mean \pm standard deviation (S.D.) $(n=12)$.

\section{Supplementary Files}

This is a list of supplementary files associated with this preprint. Click to download.

- Table1.JPG

- Table1.JPG

- Table2.JPG

- Table2.JPG

- Table3.JPG

- Table3.JPG 
- Table4.JPG

- Table4.JPG

- Additionalfile1.pdf

- Additionalfile1.pdf 